\title{
Change in Soil and Forest Floor Carbon after Shelterwood Harvests in a New England Oak-Hardwood Forest, USA
}

\author{
Kayanna L. Warren and Mark S. Ashton \\ School of Forestry and Environmental Studies, Yale University, 195 Prospect Street, New Haven, CT 06511, USA \\ Correspondence should be addressed to Mark S. Ashton; mark.ashton@yale.edu
}

Received 7 December 2013; Revised 13 March 2014; Accepted 27 March 2014; Published 6 May 2014

Academic Editor: Timothy Martin

Copyright ( 92014 K. L. Warren and M. S. Ashton. This is an open access article distributed under the Creative Commons Attribution License, which permits unrestricted use, distribution, and reproduction in any medium, provided the original work is properly cited.

\begin{abstract}
There has been effort worldwide to quantify how much carbon forests contain in order to designate appropriate offset credits to forest carbon climate mitigation. Carbon pools on or immediately below the soil surface are understood to be very active in response to environmental change but are not well understood. Our study focused on the effects of shelterwood regeneration harvests in New England on the carbon stored in litter, woody debris, and surface soil carbon. Results demonstrate significant difference in surface $(0-10 \mathrm{~cm})$ soil carbon between control (nonharvested) and harvested sites, with higher carbon percentage on control sites. Results showed a significant difference in coarse woody debris with higher amounts of carbon per area on harvested sites. No significant difference in litter mass was recorded between harvested and control sites. When coarse woody debris and litter are included with soil carbon, total carbon did not have a significant decline over 20 years following shelterwood treatment to the forest to secure regeneration, but there was considerable variability among sites. When taking all surface soil carbon measurements together, our results suggest that for accounting purposes the measurement of below-ground carbon after shelterwood harvests is not necessary for the southern New England region.
\end{abstract}

\section{Introduction}

The terrestrial carbon cycle takes up a considerable amount of atmospheric carbon, especially $\mathrm{CO}_{2},[1,2]$, the increase of which has been cited as the main driver of global climate change $[3,4]$. Maintenance of forest cover and reduction of deforestation rates have been proposed by numerous studies and policy processes as a means to reduce the magnitude of climate change [5-7]. It is therefore important that belowground carbon pools are well understood.

Persistent lack of clarity surrounds much of the efforts to tabulate, quantify, and account for the amount of carbon that is stored by forest ecosystems and thus makes its inclusion in policy protocols and its accounting expensive and challenging [8-11]. There is ongoing debate about how management affects overall carbon, with some studies suggesting that old growth forests store more carbon [12-16] while other studies find that continuous timber harvests reduce atmospheric carbon levels more $[7,17]$. However, the effects of anthropogenic disturbance, such as harvest, on belowground carbon quantity - belowground pools-is still largely unknown and thinly researched [18-22]. Only a handful of studies on soil carbon pools represent all tropical forests combined, with most studies confined to temperate regions, and most of these are from tree plantations that examine the surface soils only [22]. For temperate forests primary obstacles to quantifying soil carbon include the slow rate of carbon accumulation [23] and the spatial variability of soil $[7,24-26]$.

However, even though little research has focused on below-ground carbon, studies suggest forest soils, litter, and coarse woody debris may comprise half of terrestrial carbon storage and over two-thirds of forest carbon pools $[1,23,27$, 28]. Temperate forests in the eastern United States may be a significant carbon sink [29].

Studies on the effects of timber harvest on soil carbon have yielded mixed results thus far [30-32]. For example, soil carbon that is initially lost may take a few years to hundreds of years to recover depending upon forest type, climate, and soil condition [30,33-35]. Other studies report that soil carbon is not necessarily lost at all $[27,36,37]$. In a recent study Johnson 
et al. [38] found a consistent drop in soil carbon after a timber harvest for a northern hardwood forest in New England. Carbon accretion in soils of regenerating forests may be further limited by soil texture and other environmental conditions [39]. Information on second-growth hardwood forests is particularly important because conclusions from studies on carbon sink quantification conflict [22].

Higher rates of carbon loss occur in the forest floor more than in the soil for hardwood forests $[40,41]$. The reasons for changes in soil carbon relate strongly to litter inputs, decomposition, and respiration $[42,43]$. Studies suggest that net soil carbon storage may be influenced by small changes in climate and soil condition $[41,44]$. Over time and under the colder, wetter climate conditions the shift of live biomass into woody debris, litter, and soil humus may build up stored carbon in soils [7]. Studies conflict over whether forest floor and soil carbon increase or decrease after harvest, and it is unclear whether observed changes are more strongly correlated with the amount of debris left on-site or the change in efflux and respiration with disturbance of the soil $[36,45]$. Other studies have shown weak ability to correlate litterfall and belowground carbon allocation in mature temperate hardwood forests [44] and weak conversion of litter carbon into long-term forest soil carbon storage [46]. Not only are the dynamics of decomposition from coarse woody debris and litter to soil carbon quantity poorly understood, but also much remains to be researched about the long-term dynamics of soil carbon after forest harvest.

There are few studies which have examined the effects of silvicultural treatments (regeneration or thinning) on soil carbon stocks in the northeastern region of the United States $[30,47]$. Some of the limitations of these studies are that they looked only at differences between thinnings [47], were modeled [38], or were focused on coniferous forests rather than the predominant hardwood type [48]. Oak-hardwood forests of the northeastern US have shown reduced soil carbon stocks, reduced carbon in litter, and increased woody debris with harvest [49], but this study was after clearcut harvests, rather than shelterwood. In another study coarse woody debris was reduced by $17 \%$ in the long term by a selective timber harvest [50]; but such harvests have shown dramatic increases in coarse woody debris in the short term [51]. Prescriptions that purposefully leave dead wood as snags and slash have been shown to negate any loss of coarse woody debris [52].

Our study had two objectives. We wanted to first quantify the change in carbon for the uppermost layers of soil and surface horizons (coarse woody debris and litter) after shelterwood regeneration harvests in a second-growth oakhardwood forest. Second, we wanted to document the change in soil carbon, coarse woody debris, and litter over time after shelterwood harvests. We sought to understand how soil carbon is affected by forest harvest and how surface carbon is partitioned between coarse woody debris and litter decomposition over a 20-year time horizon after harvest. Our study focuses on the most common type of forest regeneration harvest for oak forests in the northeastern United States: shelterwoods, a method of harvest that retains a limited canopy of masting nut trees (oak, hickory, and beech) to provide seed for dispersal and germination and shelter for newly established seedlings $[53,54]$. We expected that surface carbon dynamics will show significant declines similar to findings by Covington [30] and to US Forest Service data from clearcuts. We also expected rate and amount of decline to be lower than in a clearcut because of the moderating shade from tree retention in shelterwood systems. Lastly we predicted that the surface carbon pools will decline with the most significant change in the surface litter.

\section{Methods}

2.1. Site Description of the Study Area. This study was conducted at the 3173-ha Yale-Myers Forest near Eastford, CT, in the northeastern United States $\left(41^{\circ} 57^{\prime} \mathrm{N}, 72^{\circ} 07^{\prime} \mathrm{W}\right)$. The YaleMyers Forest is a research and demonstration forest managed by the School of Forestry and Environmental Studies and owned by Yale University. The forest overstory is predominantly oak-maple-pine. The climate is characterized as cool temperate and humid. Mean annual summer temperature is $20^{\circ} \mathrm{C}$, and mean annual winter temperature is $-4^{\circ} \mathrm{C}$. Precipitation is evenly distributed throughout the year with a mean of $110 \mathrm{~cm}[55,56]$. This is a moist temperate forest underlain by a metamorphic bedrock of schist/gneiss and overlain with soils that originated from till and fluvial sediments of the last Wisconsin glacial period 20,000 b.p. [55]. The soils are mostly coarse-loamy, mesic Typic Dystrudepts [57]. The topography is characterized by undulating hills with broad ridges and narrow valleys. The elevation ranges from a low point of $170 \mathrm{~m}$ above sea level to a high point of $300 \mathrm{~m}$ above sea level [56].

Starting in the early 18 th century, the forest, as with many areas of New England, had a long period of agricultural use with land used for various kinds of improved and unimproved pasture, tilled for crops, or relict forest patches that were used as woodlots. Since the 1820s this land has largely been reforested naturally [55].

2.2. Treatment Description. All stands for our study were on glacial till soils of ablation origin and comprising the Charlton-Chatfield series [57]. This soil series is a dominant one for the oak-hardwood of southern New England making our study results generalizable to a much larger region than the forest. All study stands were originally cleared for marginal pasture but were never plowed. After abandonment in the 1850 s these sites transformed to eastern white pine (Pinus strobus L.) and were then cutover in the early 1900s for the pine boxwood industry. After cutting the pine, understory hardwood regeneration comprising oaks, hickories, birches, and maples was released. Today this second-growth hardwood forest varies in age between 90 and 110 years of age. This age class and forest history are very representative of the southern New England area.

Using available GIS maps of soil type and harvests within Yale-Myers, a map of shelterwood harvests and reserves of similar land use history (as described above) overlain with the Charlton-Chatfield soil type was created to identify sites that had suitable treated and control plots adjacent to each other (Figure 1). Controls were therefore selected as 


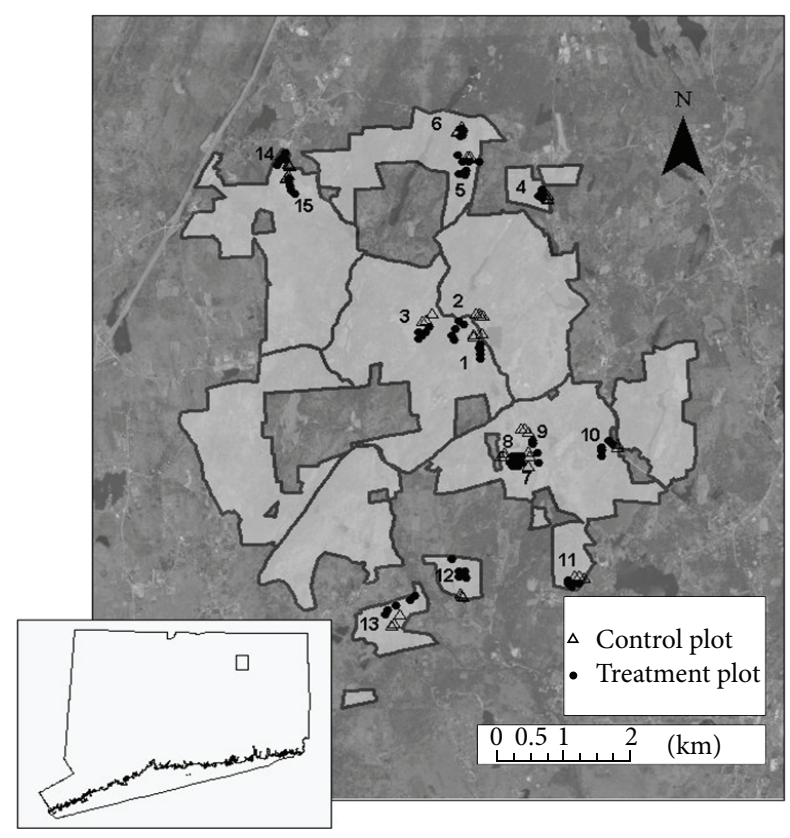

FIGURE 1: Locations of each of the 15 shelterwood treatment and adjacent control sites in the Yale-Myers Forest.

an uncut reference of similar cover, soil, land use history, and topographic position adjacent to each shelterwood harvest treatment. We did paired comparisons of treated versus control plots to determine if there is a statistical difference (at the 0.05 level or greater) between shelterwood harvest and no harvest. Harvested sites were selected to represent a range of ages from 0 to 20 years since harvest and so can be regarded as surrogates to investigate effects of age.

At the Yale-Myers Forest, shelterwood harvests reduce the canopy in a single cutting from a fully stocked basal area of about $37 \mathrm{~m}^{2} /$ ha to about $11 \mathrm{~m}^{2} /$ ha, largely comprising about forty $50-60 \mathrm{~cm}$ dbh well-spaced trees per ha. The aim is to maintain species diversity among regenerating trees and seed sources by insuring the heavy seeded masting trees (oaks, hickories, and beech) adequately disperse seeds and that the partial shade of the canopy will moderate the harsh open conditions during germination and seedling establishment. Seven to eight years later half the standing trees (basal area = $5 \mathrm{~m}^{2} / \mathrm{ha}$ ) are removed in a second and final cut leaving the rest as irregular structures to grow within the new regenerating stand. Harvest operations are generally undertaken during winter months, when the ground is frozen and covered with snow. Skid trails and landings are designated ahead of operations, often utilizing previous trails and historic roads.

2.3. Sampling Design. We selected fifteen study sites, comprising pairs of treated and control plots. Based on a prior study on soils within this forest, the range was expected to lie between 1.0 and $7.5 \mathrm{~kg} \mathrm{~m}^{2}$ of carbon in the top $30 \mathrm{~cm}$ [58], with a world average around $11.7 \mathrm{~kg} \mathrm{~m}^{2}$ of carbon for all soils to $100 \mathrm{~cm}$ depth [59]. This study estimated that northeastern temperate soils, less carbon-rich than boreal soils in Canada, would have a spread toward the lower end of that range. The sample size for each treatment block was selected with the University of Iowa's online sample size calculator [60] with settings for two-way ANOVA. Using this estimation, a sample of five and three plots was determined for the treated and control sites, respectively. Individual plots on each site were selected using a random number generator and a GPS coordinate grid.

Plots were centered at the GPS coordinates. Plot corners were defined as three meters north, east, south, and west of the plot center. Two $2.54 \mathrm{~cm}$ wide soil cores were taken at each point (center, north, south, east, and west) and pooled into one plot sample (Figure 2). Because the upper soil horizon has more carbon than other increments of the mineral soil at deeper levels [58] and because most of the observable change 20 years after harvest was expected to be in the upper $10 \mathrm{~cm}$ $[58,61]$, we cored to a depth of $10 \mathrm{~cm}$ at each core point from the mineral soil surface and below the litter and organic soil horizon. This meant that we carefully scraped of the organic horizon to carefully identify the mineral soil surface layer. The forest floor organic horizon was sampled using a $15 \mathrm{~cm} \times$ $15 \mathrm{~cm}$ square template that allowed removal of the complete incorporated and unincorporated litter from the center of the plots. This included all detritus and dead wood less than $2.5 \mathrm{~cm}$ in diameter. This material was bagged and taken to the lab for processing. In addition all coarse woody debris greater than $2.5 \mathrm{~cm}$ in diameter was measured for length and diameter but only for material that was within the $4.24 \mathrm{~m} \times$ $4.24 \mathrm{~m}$ plot. Woody debris volume was calculated based on the volume of a cylinder. Lastly, tree species was recorded and an estimation of basal area was taken using a variable radius plot protocol and a $2 \mathrm{BAF}$ metric angle gauge to characterize stand structure and composition and to insure there were no differences across sites and treatments [62].

2.4. Soil Measurements and Analysis. In the field, soil core depth was measured to calculate total soil volume of the collected cores. In the lab, the wet and dry weights, the percent moisture and percent carbon were determined. While there are difficulties with assessing total carbon losses by using percent carbon, other studies have demonstrated that it can be used as a proxy [63]. Soil was sieved in the lab to $2 \mathrm{~mm}$ using the protocol of Bradford et al. [64]. The dried soil samples were sent to the Ecology Lab at the University of Georgia, where carbon content of each sample was determined using a micro-Dumas flash combustion, CHN Analyzer, essentially combusting soil components and measuring carbon via gas $\left(\mathrm{CO}_{2}\right)$ release [64]. Carbon per unit forest area was calculated with the following equation:

$$
\begin{aligned}
& \mathrm{C}\left(\frac{\mathrm{Mg}}{\mathrm{ha}}\right) \\
& =\left[\text { soil bulk density }\left(\mathrm{g} / \mathrm{m}^{3}\right) \times \text { soil depth }(\mathrm{m}) \times \mathrm{C}\right] \\
& \quad \times 100 \times \frac{10000 \mathrm{~m}^{2}}{1 \mathrm{ha}} \times \frac{1 \mathrm{Mg}}{1000000 \mathrm{~g}} .
\end{aligned}
$$

See [65]. After initial tests of bulk density in our plots, our measurements corroborated those of Kulmatiski et al. [58]. 


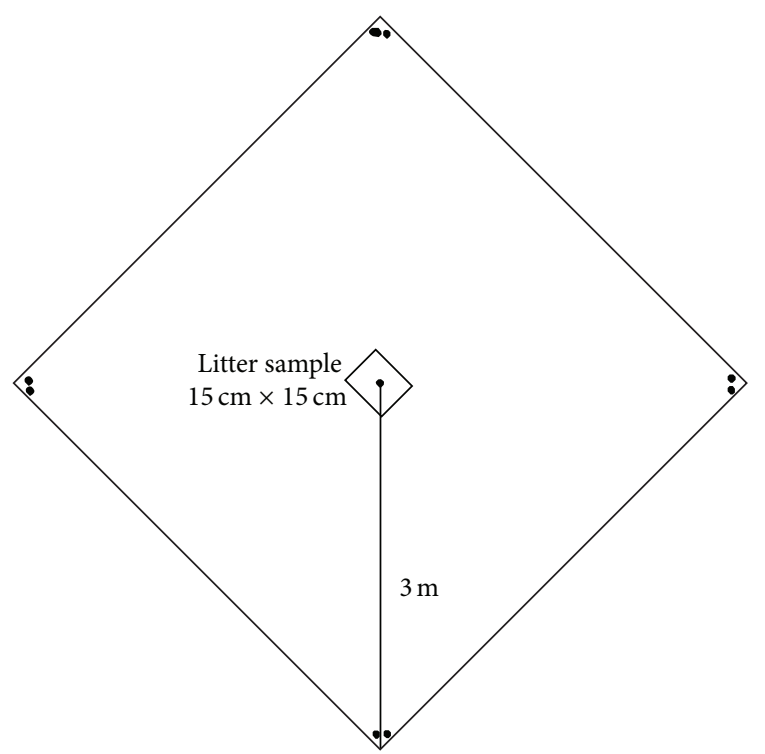

Figure 2: Diagram of plot design. Two soil cores were taken at the center and at each corner.

Using both our initial tests and a penetrometer we found no evidence of differences in bulk densities between our treatment and control for each our sites or across all our sites more generally. We therefore used 0.81 , from an average surface soil bulk density for the Yale-Myers Forest [58]. We used the Kulmatiski et al. [58] measure of soil bulk density because it was based on a much more substantial soil survey of the forest soils at Yale-Myers than our study.

Litter mass was measured wet and then dried in the laboratory at $80^{\circ} \mathrm{C}$ for 48 hours [66]. Carbon content was found by converting a ratio of carbon to dried material for litter and, through additional steps, for coarse woody debris. Biomass was assumed to comprise $49.8 \%$ of the wood volume for coarse woody debris and $50 \%$ of the mass for dry litter for oak-hickory stands in the northeastern US [67]. Specific wood density was estimated at 0.636 [67] in this study. There are lower estimates from US Forest Inventory and Analysis (FIA) data but we selected a higher value given the larger proportion of slower growing denser woods within our forest [68].

Based on field observation, decay classes were assigned an average decay class of two for harvested plots younger than six years, a decay class of three for harvested plots six years or greater, and a decay class of three for control sites. Our approach was a simplified protocol using the Brown et al. [65] decay classification and decay coefficients from Waddell [69]. The equation to convert volume of coarse woody debris per plot to carbon mass per area was

$$
\begin{array}{r}
\frac{\mathrm{C}(\mathrm{g})}{\operatorname{area}\left(\mathrm{m}^{2}\right)}=\left[\text { volume, }\left(\mathrm{m}^{3}\right) *\right. \text { specific gravity } \\
\\
\text { *biomass ratio } * \text { decay class }] .
\end{array}
$$

2.5. Data Analysis. The fifteen sites were treated as paired replicates (control and shelterwood harvest) using a two-way ANOVA using R, version 2.12.2 [70]. The model comprised treatment (harvest, control), sites over time (1-20 years), and an interaction term (treatment $\times$ site). Variables analyzed included (i) percent soil carbon in the top $10 \mathrm{~cm}$; (ii) carbon in the litter and forest floor; (iii) estimated carbon in coarse woody debris; and (iv) all pools combined. All soil carbon and litter data was nonnormally distributed and was log-transformed while coarse woody data was cube-roottransformed prior to analysis. We used Tukey's studentized $t$-test to compare levels of significance among treatments for all variables we tested. In addition, regression analysis was used to explore change in carbon over time to determine if a relationship exists in surface and soil carbon and time since harvest treatment.

\section{Results}

3.1. Comparisons in Carbon Pools between Shelterwood Harvest and Control Sites. Harvested sites were shown to have significantly lower amounts of surface soil carbon (carbon in the top $30 \mathrm{~cm}$ of the soil) $\left(6.01 \mathrm{~kg} \mathrm{~m}^{2}\right)$ than control sites $\left(8.36 \mathrm{~kg} \mathrm{~m}^{2}\right)$ that were left intact and there was significant difference among sites and in interaction between treatments and sites (Figure 3, Table 1).

Shelterwood harvest also had an impact on coarse woody debris. Harvest treatments had a significantly greater amount of carbon in coarse woody debris $\left(3.16 \mathrm{~kg} \mathrm{~m}^{2}\right)$ as compared to unharvested controls $\left(0.62 \mathrm{~kg} \mathrm{~m}^{2}\right)$ (Figure 3, Table 1$)$, but again significant differences were shown among sites and in interactions between site and treatment. Total carbon in litter per unit area was found to have a significant difference between harvested $\left(0.59 \mathrm{~kg} \mathrm{~m}^{2}\right)$ and unharvested controls $\left(0.47 \mathrm{~kg} \mathrm{~m}^{2}\right)$ (Figure 3, Table 1). But no difference was shown among sites and interactions between site and treatment.

When surface soil carbon was combined with carbon in litter and coarse woody debris on a mass per unit area, no significant difference between shelterwood harvested treatments and unharvested controls could be demonstrated (Figure 3, Table 1). However, there was a significant difference among sites and in an interaction between treatment and site, indicating that sites (as surrogates for time since shelterwood cut) not only had different starting carbon stocks but also responded differently to harvests over time.

\subsection{Comparisons in Carbon Pools over Time for Shelterwood} Harvest and Control Sites. Downward trends in carbon content for sites over time since harvest were seen for all three pools but with a weak $R^{2}$ value when analyzed with a linear regression model (Figure 4). However, $P$ values were significant for the harvested trend lines for both the coarse woody debris and total pooled carbon, indicating a downward trend in both of these pools over time and supporting the contention that time since harvest is the interacting effect in the results for the ANOVA. Coarse woody debris was the most significant with a decline from $4.5 \mathrm{~kg} \mathrm{~m}^{2}$ to $0.40 \mathrm{~kg} \mathrm{~m}^{2}$ over the twenty-year period suggesting that 


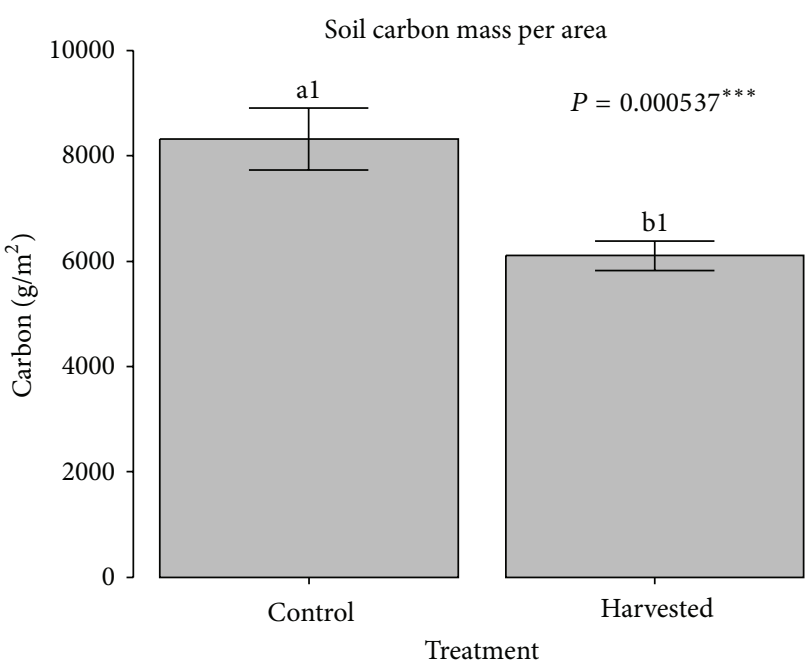

(a)

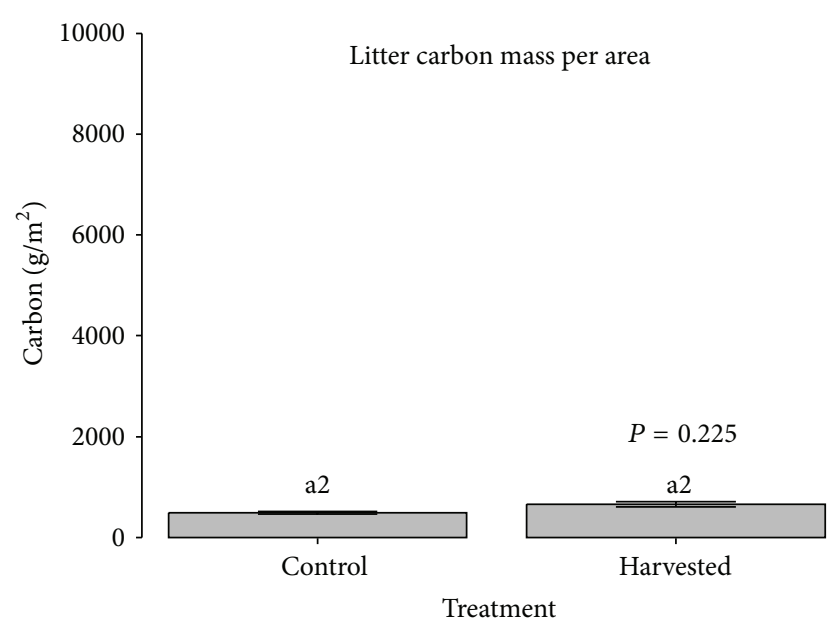

(b)

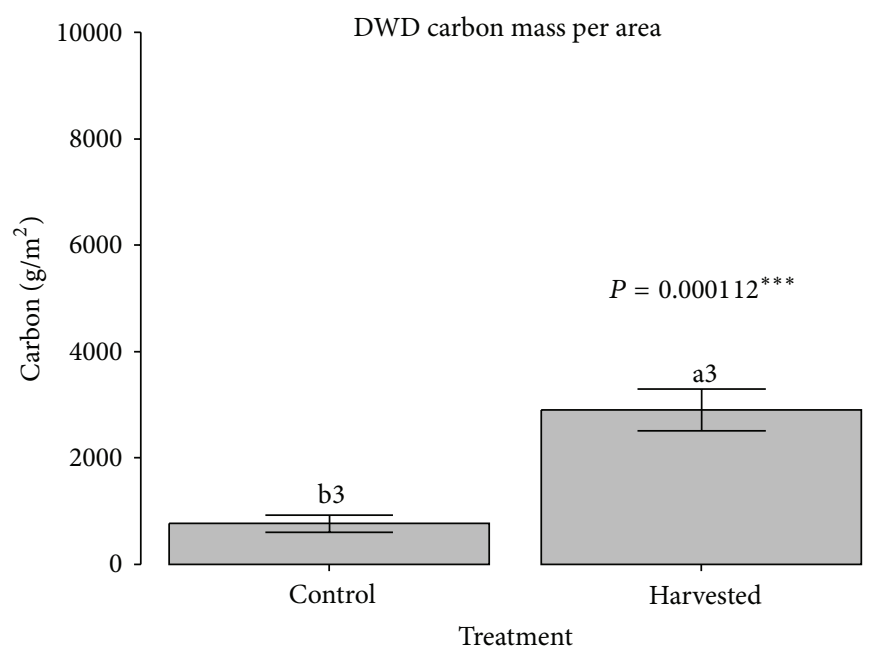

(c)

Figure 3: Mass per area of each carbon pool by treatment. Tukey paired $t$-tests between the variables indicate level of significance at 0.05 level whereby a $>$ b. Different letters indicate significant difference.

it had reached control baseline levels of unharvested sites within this time frame. Soil carbon and litter suggested a weak downward trend over time relative to the control but both were not significant.

\section{Discussion}

The results indicate that soil carbon pools significantly declined after shelterwood harvest but that total soil carbon mass per area in the top $10 \mathrm{~cm}$ showed no significant difference as compared to uncut controls. Carbon mass per area of coarse woody debris was found to increase significantly after harvest, as expected. Furthermore, the difference between more recently cut sites and older sites appeared to narrow, as expected with the decomposition of woody material. It could be concluded that over the 20-year period of shelterwood harvests differences in amount of coarse woody debris could be related to changes in site treatment (e.g., prescribed burning, whole-tree chipping, etc.). We can attest that no changes occurred. All site treatments were the same with all stems and tops less than $20 \mathrm{~cm}$ dbh being left purposefully scattered across the harvest sites. However, this trend may have been more accurately depicted if woody debris volume had been individually classified to a decay class rather than pooled to particular years since harvest. Litter carbon was not shown to be significantly different between shelterwood harvest and control plots, although it was shown to be generally higher than US Forest Service estimates for postharvest oak-hickory forests in the northeast [49]. Coarse woody debris, however, was shown to be less for those forest service estimates [49], which in turn were less than those found by Covington [30]. The difference between our results and those of Covington [30] and Smith et al. [49] could be attributed to method of harvest (shelterwood versus clearcut) or to differences in measurement protocols and sampling design. 
TABLE 1: ANOVA of soil, litter, and coarse woody debris (CWD) carbon mass per area by treatment.

\begin{tabular}{lcccccccrr}
\hline & \multirow{2}{*}{ df } & \multicolumn{2}{c}{ Surface soil } & \multicolumn{2}{c}{ Litter } & \multicolumn{2}{c}{ CWD } & \multicolumn{2}{c}{ Total } \\
& & $F$ value & $P$ & $F$ value & $P$ & $F$ value & $P$ & $F$ value \\
\hline Treatment & 1 & 28.273 & $0.000^{* * *}$ & 5.5742 & $0.020^{*}$ & 25.314 & $0.000^{* * *}$ & 0.024 \\
Site & 14 & 5.188 & $0.000^{* * *}$ & 1.5889 & 0.099 & 3.868 & $0.000^{* * *}$ & 2.977 \\
Treatment $\times$ site & 14 & 4.649 & $0.000^{* * *}$ & 1.2263 & 0.272 & 2.041 & $0.024^{*}$ & 3.887 & $0.001^{* * *}$ \\
\hline
\end{tabular}

Significance codes are as follows: ${ }^{* * *} 0.001,{ }^{* *} 0.01$, and ${ }^{*} 0.05$. Treatment refers to shelterwood harvest versus control. Site refers to replicate sites examined that span a 20 -year period since harvest.

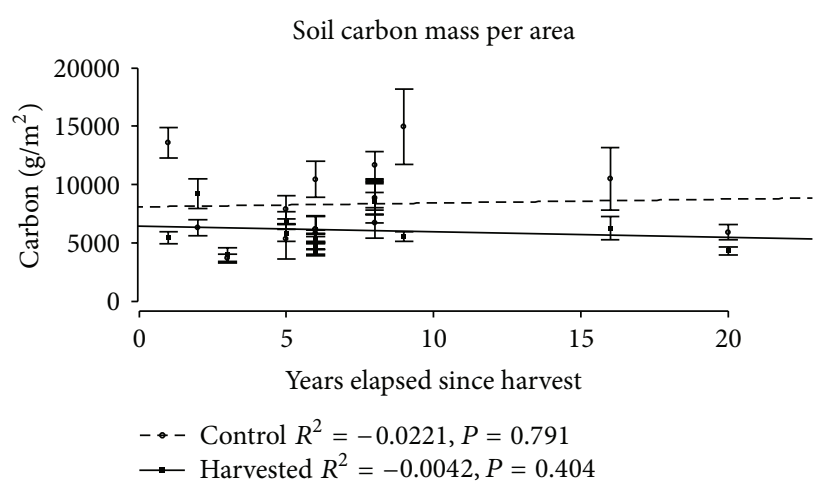

(a)

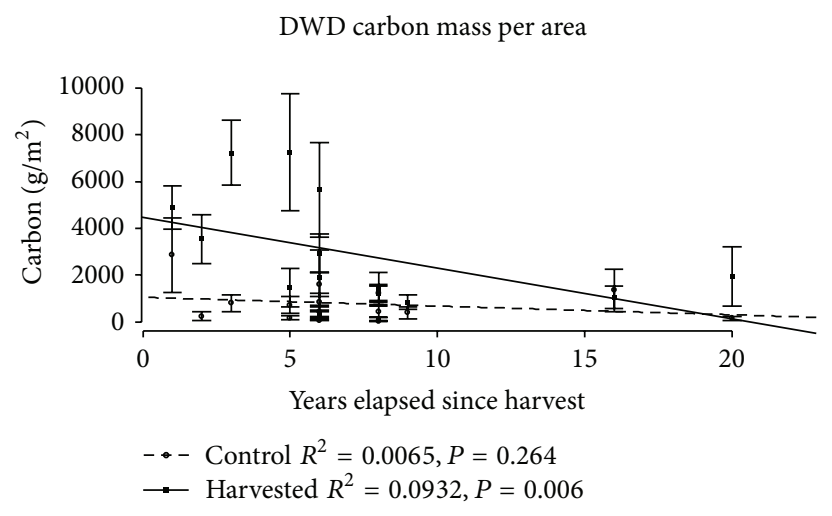

(c)

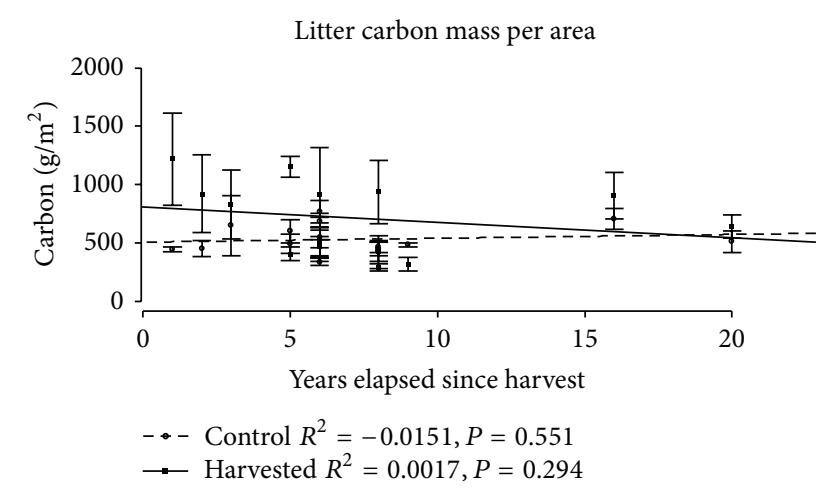

(b)

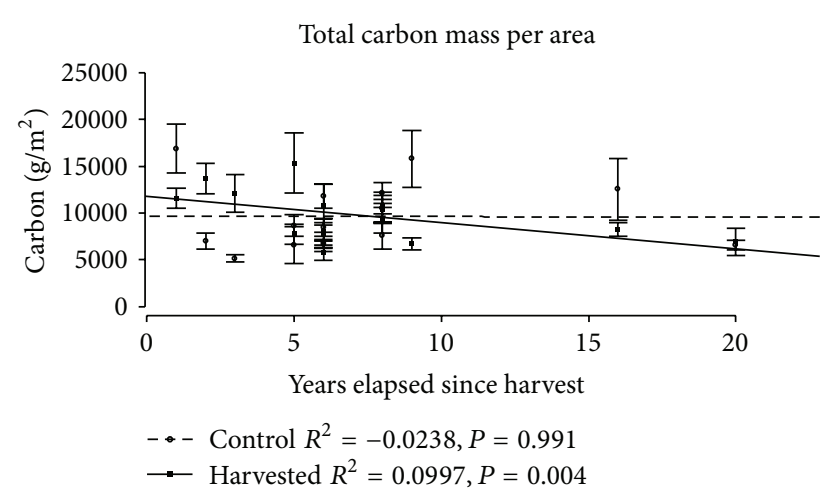

(d)

FIGURE 4: Regressions depicting mass per area change of each carbon pool over time for control and shelterwood harvested sites: (a) soil carbon change, (b) litter carbon change, (c) coarse woody debris carbon change, and (d) total carbon change for three combined pools.

Our study also showed higher on average soil carbon content as compared to a study at the same forest by Kulmatiski et al. [71] whose objective was to quantify total soil carbon at depth. The Kulmatiski et al. [71] study was forest wide, irrespective of soil type. On average, it also sampled soil three times deeper than our study. Our soil cores went to a $10 \mathrm{~cm}$ depth because our focus was the effects of harvesting on carbon in surface horizons. They also found topographic position accounted for $18 \%$ of soil carbon variation, with wetter lower lying areas containing more carbon than drier upland soils. Furthermore, carbon content, bulk density, and depth are correlated [72] and further research needs to be done to measure each of these variables to verify and refine more accurate calculations for soil carbon content unique to each site.
The difference in total carbon stocks between control and harvested sites, however, was not found to be significant when pooling together all sites of varying time since harvest. The potential reason for the lack of significance is the dynamic change among the different carbon pools, some increasing and some decreasing over time. While coarse woody debris represented a smaller carbon pool than mineral soil carbon, the large increase counterbalanced the soil carbon decrease. Litter was the smallest carbon pool and also experienced no significant change. However, when examining trends over the 20-year time period total carbon among all pools (soil, litter, and debris) showed a significant decline. This was primarily due to coarse woody debris which showed the only significant downward trend over time. The trend line for mineral soil carbon and litter suggested a downward trend over time 
relative to the control but was not significant. Obtaining data from older harvests may have strengthened this relationship but no sites exist.

Overall, these results indicate that these three pools are a significant portion of total carbon stocks but that the changes that may occur due to harvest represent a relatively small portion of total site carbon stocks. Coarse woody debris showed the strongest significant change with shelterwood harvest, but it was a smaller pool than soil carbon. Surface soil carbon significantly declined in the top $10 \mathrm{~cm}$, but further studies that extend over a longer time period will be important to do.

\section{Conclusions}

Taking all sites together, total pools of carbon (litter, woody debris, and surface soil carbon) showed no significant decline with harvest primarily because declines in surface soil carbon and litter were more than made up for by increases in coarse woody debris. However, when comparing sites with time since shelterwood harvest, there are significant declines in total carbon. Our results show this is strongly driven by decline in coarse woody debris. There are also significant declines in surface soil carbon with harvest, but there is considerable variability between sites, and this trend is weak with time since harvest. These results suggest that for the purposes of forest carbon accounting auditors do not need to monitor changes in below-ground carbon stocks with shelterwood harvests for this region. We believe there is not enough of a significant decline or change in carbon to merit the time and cost in measurement.

\section{Conflict of Interests}

The authors declare that there is no conflict of interests regarding the publication of this paper.

\section{Acknowledgments}

The authors would like to thank the Carpenter-Sperry Fund and the Jubitz Family Fund for supporting this study. They would also like to thank Mark Bradford, Elaine Hooper, Jonathan Reuning-Scherer, Meredith Martin, and Dan Constable for their advice on soil sampling methodology, statistical methodology, and GIS mapping layout.

\section{References}

[1] R. K. Dixon, S. Brown, R. A. Houghton, A. M. Solomon, M. C. Trexler, and J. Wisniewski, "Carbon pools and flux of global forest ecosystems," Science, vol. 263, no. 5144, pp. 185-190, 1994.

[2] Y. Pan, R. A. Birdsey, J. Fang et al., "A large and persistent carbon sink in the world's forests," Science, vol. 333, no. 6045, pp. 988993, 2011.

[3] D. Eamus and P. G. Jarvis, "The direct effects of increase in the global atmospheric $\mathrm{CO}_{2}$ concentration on natural and commercial temperate trees and forests," Advances in Ecological Research C, vol. 19, pp. 1-55, 1989.
[4] IPCC (Intergovernmental Panel on Climate Change), Climate Change 2007: The Physical Science Basis. Contribution of Working Group I to the Fourth Assessment Report of the Intergovernmental Panel on Climate Change. IPCC, Geneva, Switzerland, 2010, http://www.ipcc.ch/.

[5] R. Bradley, B. Childs, T. Herzog, J. Pershing, and K. A. Baumert, Slicing the Pie: Sector-Based Approaches to International Climate Agreements, World Resources Institute, Washington, DC, USA, 2007.

[6] G. R. van der Werf, D. C. Morton, R. S. Defries et al., " $\mathrm{CO}_{2}$ emissions from forest loss," Nature Geoscience, vol. 2, no. 11, pp. 737-738, 2009.

[7] T. J. Fahey, P. B. Woodbury, J. J. Battles et al., "Forest carbon storage: ecology, management, and policy," Frontiers in Ecology and the Environment, vol. 8, no. 5, pp. 245-252, 2010.

[8] F. García-Oliva and O. R. Masera, "Assessment and measurement issues related to soil carbon sequestration in land-use, land-use change, and forestry (LULUCF) projects under the Kyoto protocol," Climatic Change, vol. 65, no. 3, pp. 347-364, 2004.

[9] R. A. Birdsey, "Carbon accounting rules and guidelines for the United States forest sector," Journal of Environmental Quality, vol. 35, no. 4, pp. 1518-1524, 2006.

[10] A. Gershenson and J. Barsimantov, "Accounting for carbon in soils," Climate Action Reserve White Paper, 2010.

[11] J. S. Nunery and W. S. Keeton, "Forest carbon storage in the northeastern United States: net effects of harvesting frequency, post-harvest retention, and wood products," Forest Ecology and Management, vol. 259, no. 8, pp. 1363-1375, 2010.

[12] M. E. Harmon, W. K. Ferrell, and J. F. Franklin, "Effects on carbon storage of conversion of old-growth forests to young forests," Science, vol. 247, no. 4943, pp. 699-702, 1990.

[13] J. H. M. Thornley and M. G. R. Cannell, "Managing forests for wood yield and carbon storage: a theoretical study," Tree Physiology, vol. 20, no. 7, pp. 477-484, 2000.

[14] B. E. Law, P. E. Thornton, J. Irvine, P. M. Anthoni, and S. Van Tuyl, "Carbon storage and fluxes in ponderosa pine forests at different developmental stages," Global Change Biology, vol. 7, no. 7, pp. 755-777, 2001.

[15] E. A. H. Smithwick, M. E. Harmon, S. M. Remillard, S. A. Acker, and J. F. Franklin, "Potential upper bounds of carbon stores in forests of the Pacific Northwest," Ecological Applications, vol. 12, no. 5, pp. 1303-1317, 2002.

[16] S. Luyssaert, E.-D. Schulze, A. Börner et al., "Old-growth forests as global carbon sinks," Nature, vol. 455, no. 7210, pp. 213-215, 2008.

[17] D. Markewitz, "Fossil fuel carbon emissions from silviculture: impacts on net carbon sequestration in forests," Forest Ecology and Management, vol. 236, no. 2-3, pp. 153-161, 2006.

[18] K. I. Paul, P. J. Polglase, J. G. Nyakuengama, and P. K. Khanna, "Change in soil carbon following afforestation," Forest Ecology and Management, vol. 168, no. 1-3, pp. 241-257, 2002.

[19] S. Schmid, B. Zierl, and H. Bugmann, "Analyzing the carbon dynamics of central European forests: comparison of BiomeBGC simulations with measurements," Regional Environmental Change, vol. 6, no. 4, pp. 167-180, 2006.

[20] Z. Xu and G. Chen, "Fingerprinting global climate change and forest management within rhizosphere carbon and nutrient cycling processes," Environmental Science and Pollution Research, vol. 13, no. 5, pp. 293-298, 2006. 
[21] R. Jandl, M. Lindner, L. Vesterdal et al., "How strongly can forest management influence soil carbon sequestration?" Geoderma, vol. 137, no. 3-4, pp. 253-268, 2007.

[22] S. P. Price, M. A. Bradford, and M. S. Ashton, "Characterizing organic carbon stocks and flows in forest soils," in Managing Forest Carbon in a Changing Climate, M. S. Ashton, M. L. Tyrrell, D. Spalding, and B. Gentry, Eds., pp. 7-30, Springer, New York, NY, USA, 2012.

[23] W. M. Post, R. C. Izaurralde, L. K. Mann, and N. Bliss, "Monitoring and verifying changes of organic carbon in soil," Climatic Change, vol. 51, no. 1, pp. 73-99, 2001.

[24] P. S. Homann, B. T. Bormann, and J. R. Boyle, "Detecting treatment differences in soil carbon and nitrogen resulting from forest manipulations," Soil Science Society of America Journal, vol. 65 , no. 2, pp. 463-469, 2001.

[25] K. M. Carney, B. A. Hungate, B. G. Drake, and J. P. Megonigal, "Altered soil microbial community at elevated $\mathrm{CO}_{2}$ leads to loss of soil carbon," Proceedings of the National Academy of Sciences of the United States of America, vol. 104, no. 12, pp. 4990-4995, 2007.

[26] N. P. A. Saby, P. H. Bellamy, X. Morvan et al., "Will European soil-monitoring networks be able to detect changes in topsoil organic carbon content?" Global Change Biology, vol. 14, no. 10, pp. 2432-2442, 2008.

[27] D. W. Johnson and P. S. Curtis, "Effects of forest management on soil C and N storage: meta analysis," Forest Ecology and Management, vol. 140, no. 2-3, pp. 227-238, 2001.

[28] C. L. Goodale, M. J. Apps, R. A. Birdsey et al., "Forest carbon sinks in the Northern Hemisphere," Ecological Applications, vol. 12, no. 3, pp. 891-899, 2002.

[29] C. C. Barford, S. C. Wofsy, J. W. Munger et al., "Factors controlling long- and short-term sequestration of atmospheric $\mathrm{CO}_{2}$ in a mid-latitude forest," Science, vol. 294, no. 5547, pp. 1688-1691, 2001.

[30] W. W. Covington, "Changes in forest floor organic-matter and nutrient content following clear cutting in northern hardwoods," Ecology, vol. 62, no. 1, pp. 41-48, 1981.

[31] K. G. Harrison, W. M. Post, and D. D. Richter, "Soil carbon turnover in a recovering temperate forest," Global Biogeochemical Cycles, vol. 9, no. 4, pp. 449-454, 1995.

[32] R. D. Yanai, M. A. Arthur, T. G. Siccama, and C. A. Federer, "Challenges of measuring forest floor organic matter dynamics: repeated measures from a chronosequence," Forest Ecology and Management, vol. 138, no. 1-3, pp. 273-283, 2000.

[33] T. A. Black and J. W. Harden, "Effect of timber harvest on soil carbon storage at Blodgett experimental forest, California," Canadian Journal of Forest Research, vol. 25, no. 8, pp. 13851396, 1995.

[34] J. Shan, L. A. Morris, and R. L. Hendrick, "The effects of management on soil and plant carbon sequestration in slash pine plantations," Journal of Applied Ecology, vol. 38, no. 5, pp. 932-941, 2001.

[35] R. Lal, "Forest soils and carbon sequestration," Forest Ecology and Management, vol. 220, no. 1-3, pp. 242-258, 2005.

[36] K. G. Mattson and W. T. Swank, "Soil and detrital carbon dynamics following forest cutting in the Southern Appalachians," Biology and Fertility of Soils, vol. 7, no. 3, pp. 247-253, 1989.

[37] R. D. Yanai, S. V. Stehman, M. A. Arthur et al., "Detecting change in forest floor carbon," Soil Science Society of America Journal, vol. 67, no. 5, pp. 1583-1593, 2003.
[38] K. Johnson, F. N. Scatena, and Y. Pan, "Short- and longterm responses of total soil organic carbon to harvesting in a northern hardwood forest," Forest Ecology and Management, vol. 259, no. 7, pp. 1262-1267, 2010.

[39] D. D. Richter, D. Markewitz, S. E. Trumbore, and C. G. Wells, "Rapid accumulation and turnover of soil carbon in a reestablishing forest," Nature, vol. 400, no. 6739, pp. 56-58, 1999.

[40] R. A. Houghton, "Revised estimates of the annual net flux of carbon to the atmosphere from changes in land use and land management 1850-2000," Tellus B: Chemical and Physical Meteorology, vol. 55, no. 2, pp. 378-390, 2003.

[41] L. E. Nave, E. D. Vance, C. W. Swanston, and P. S. Curtis, "Harvest impacts on soil carbon storage in temperate forests," Forest Ecology and Management, vol. 259, no. 5, pp. 857-866, 2010.

[42] P. J. Hanson, N. T. Edwards, C. T. Garten, and J. A. Andrews, "Separating root and soil microbial contributions to soil respiration: a review of methods and observations," Biogeochemistry, vol. 48, no. 1, pp. 115-146, 2000.

[43] T. W. Berger, E. Inselsbacher, and S. Zechmeister-Boltenstern, "Carbon dioxide emissions of soils under pure and mixed stands of beech and spruce, affected by decomposing foliage litter mixtures," Soil Biology and Biochemistry, vol. 42, no. 6, pp. 986997, 2010.

[44] E. A. Davidson, K. Savage, P. Bolstad et al., "Belowground carbon allocation in forests estimated from litterfall and IRGAbased soil respiration measurements," Agricultural and Forest Meteorology, vol. 113, no. 1-4, pp. 39-51, 2002.

[45] G. D. Mroz, M. J. Jurgensen, and D. J. Frederick, "Soil nutrient changes following whole tree harvesting on three northern hardwood sites," Soil Science Society of America Journal, vol. 49, no. 6, pp. 1552-1557, 1985.

[46] W. H. Schlesinger and J. Lichter, "Limited carbon storage in soil and litter of experimental forest plots under increased atmospheric $\mathrm{CO}_{2}$," Nature, vol. 411, no. 6836, pp. 466-469, 2001.

[47] C. Hoover and S. Stout, "The carbon consequences of thinning techniques: stand structure makes a difference," Journal of Forestry, vol. 105, no. 5, pp. 266-270, 2007.

[48] N. A. Scott, D. Y. Hollinger, E. A. Davidson, C. A. Rodrigues, and D. B. Dail, "Impact of a shelterwood harvest on the net carbon balance of a spruce/hemlock dominated forest in Maine," in Proceedings of the New England Society of American Foresters 85th Winter Meeting, L. S. T. Kenefic and J. Mark, Eds., U.S. Department of Agriculture, Forest Service, Northeastern Research Station, Newtown Square, Pa, USA, 2005.

[49] J. E. Smith, L. S. Heath, K. E. Skog, and R. A. Birdsey, "Methods for calculating forest ecosystem and harvested carbon with standard estimates for forest types in the United States," General Technical Report NE-343, U.S. Department of Agriculture, Forest Service, Northeastern Research Station, Newtown Square, $\mathrm{Pa}$, USA, 2006.

[50] J. A. Gore and W. A. Patterson, "Mass of downed wood in northern hardwood forests in New Hampshire: potential effects of forest management," Canadian Journal of Forest Research, vol. 16, no. 2, pp. 335-339, 1986.

[51] W. H. Liu, D. M. Bryant, L. R. Hutyra et al., "Woody debris contribution to the carbon budget of selectively logged and maturing mid-latitude forests," Oecologia, vol. 148, no. 1, pp. 108-117, 2006.

[52] W. S. Keeton, "Managing for late-successional/old-growth characteristics in northern hardwood-conifer forests," Forest Ecology and Management, vol. 235, no. 1-3, pp. 129-142, 2006. 
[53] D. M. Smith, B. C. Larson, M. J. Kelty, and P. M. S. Ashton, The Practice of Silviculture: Applied Forest Ecology, John Wiley \& Sons, New York, NY, USA, 1997.

[54] B. R. Frey, M. S. Ashton, J. J. McKenna, D. Ellum, and A. Finkral, "Topographic and temporal patterns in tree seedling establishment, growth, and survival among masting species of southern New England mixed-deciduous forests," Forest Ecology and Management, vol. 245, no. 1-3, pp. 54-63, 2007.

[55] W. H. Meyer and B. Plusnin, "The Yale forest in tolland and Windham counties," Yale School of Forestry and Environmental Studies Bulletin 55, Yale School of Forestry and Environmental Studies, New Haven, Conn, USA, 1945.

[56] M. S. Ashton and B. C. Larson, "Germination and seedling growth of Quercus (section Erythrobalanus) across openings in a mixed-deciduous forest of southern New England, USA," Forest Ecology and Management, vol. 80, no. 1-3, pp. 81-94, 1996.

[57] A. Roberts, Soil Survey of Windham County, United States Department of Agriculture, Soil Conservation Service, Connecticut, Conn, USA, 1981.

[58] A. Kulmatiski, D. J. Vogt, T. G. Siccama, and K. H. Beard, "Detecting nutrient pool changes in rocky forest soils," Soil Science Society of America Journal, vol. 67, no. 4, pp. 1282-1286, 2003.

[59] J. S. Bhatti, M. J. Apps, and C. Tarnocai, "Estimates of soil organic carbon stocks in central Canada using three different approaches," Canadian Journal of Forest Research, vol. 32, no. 5, pp. 805-812, 2002.

[60] R. Lenth, "Power and sample-size page," University of Iowa Department of Statistics and Actuarial Science, 2010, http:// www.stat.uiowa.edu/ rlenth/Power/.

[61] M. S. Strickland, J. L. Devore, J. C. Maerz, and M. A. Bradford, "Grass invasion of a hardwood forest is associated with declines in belowground carbon pools," Global Change Biology, vol. 16, no. 4, pp. 1338-1350, 2010.

[62] T. E. Avery and H. E. Burkhart, Forest Measurements, McGraw Hill, New York, NY, USA, 4th edition, 1994.

[63] P. H. Bellamy, P. J. Loveland, R. I. Bradley, R. M. Lark, and G. J. D. Kirk, "Carbon losses from all soils across England and Wales 1978-2003," Nature, vol. 437, no. 7056, pp. 245-248, 2005.

[64] M. A. Bradford, N. Fierer, and J. F. Reynolds, "Soil carbon stocks in experimental mesocosms are dependent on the rate of labile carbon, nitrogen and phosphorus inputs to soils," Functional Ecology, vol. 22, no. 6, pp. 964-974, 2008.

[65] S. Brown, D. Shoch, T. Pearson, and M. Delaney, Methods for Measuring and Monitoring Forestry Carbon Projects in California, Winrock International, Arlington, Va, USA, 2004.

[66] K. G. MacDicken, A Guide to Monitoring Carbon Storage in Forestry and Agroforestry Projects, Winrock International, Arlington, Va, USA, 1997.

[67] R. A. Birdsey, Carbon Storage and Accumulation in United States Forest Ecosystems, U.S. Department of Agriculture, Forest Service, Washington, DC, USA, 1992.

[68] J. E. Smith, L. S. Heath, and P. B. Woodbury, "How to estimate forest carbon for large areas from inventory data," Journal of Forestry, vol. 102, no. 5, pp. 25-31, 2004.

[69] K. L. Waddell, "Sampling coarse woody debris for multiple attributes in extensive resource inventories," Ecological Indicators, vol. 1, no. 3, pp. 139-153, 2001.

[70] The R Development Core Team, R: A Language and Environment for Statistical Computing, The R Foundation for Statistical Computing, Vienna, Austria, 2011, http://www.R-project.org/.
[71] A. Kulmatiski, D. J. Vogt, T. G. Siccama et al., "Landscape determinants of soil carbon and nitrogen storage in southern New England," Soil Science Society of America Journal, vol. 68, no. 6, pp. 2014-2022, 2004.

[72] C. Périé and R. Ouimet, "Organic carbon, organic matter and bulk density relationships in boreal forest soils," Canadian Journal of Soil Science, vol. 88, no. 3, pp. 315-325, 2008. 

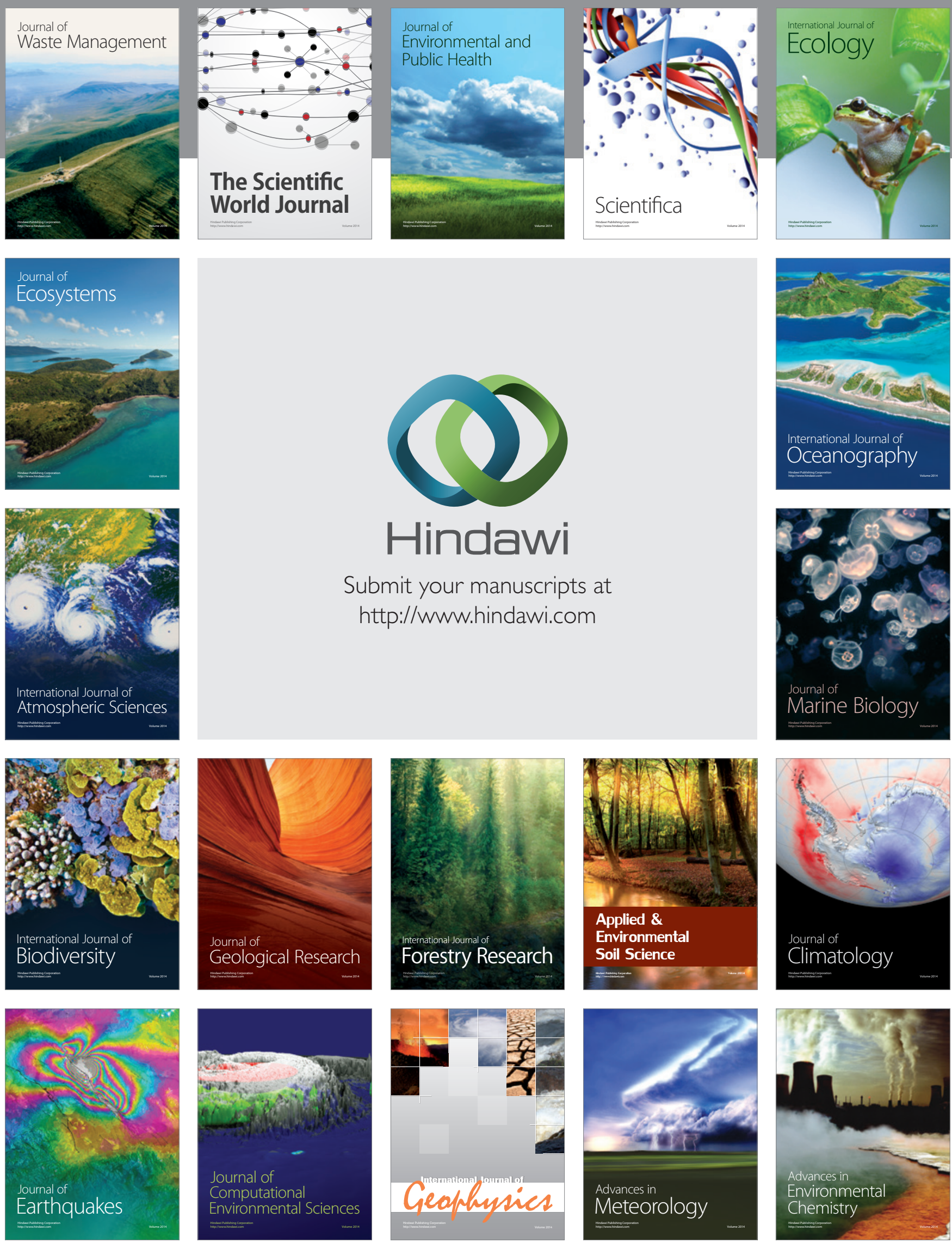